\title{
Real-World Treatment Patterns Of Cyclosporine Ophthalmic Emulsion And Lifitegrast Ophthalmic Solution Among Patients With Dry Eye
}

This article was published in the following Dove Press journal:

Clinical Ophthalmology

\author{
Darrell E White' \\ Yang Zhao ${ }^{2}$ \\ Abayomi Ogundele ${ }^{2}$ \\ Nicole Fulcher ${ }^{3}$ \\ Annabel $\mathrm{Acs}^{3}$ \\ Laura Moore-Schiltz ${ }^{3}$ \\ Paul M Karpecki ${ }^{4}$ \\ 'Department of Ophthalmology, \\ SkyVision Centers, Westlake, OH 44I45, \\ USA; ${ }^{2}$ Health Economics and Outcomes \\ Research, Sun Pharmaceutical Industries, \\ Princeton, NJ 08540, USA; ${ }^{3}$ Outcomes \\ Research, IBM Watson Health, \\ Cambridge, MA 02142, USA; ${ }^{4}$ Corneal \\ Services and Advanced OSD Clinic, \\ University of Pikeville Kentucky College \\ of Optometry, Pikeville, KY 4I50I, USA
}

Correspondence: Yang Zhao Health Economics and Outcomes Research, Sun Pharmaceutical Industries, Inc., 2 Independence Way, Princeton, NJ 08540, USA

Tel + I 6097208132

Email yang.zhao@sunpharma.com
Purpose: To assess adherence, non-persistence, discontinuation, and switching of topical cyclosporine ophthalmic emulsion $0.05 \%$ (CYC) and lifitegrast ophthalmic solution 5\% (LIF) use in the real world among patients with dry eye disease (DED).

Design: Retrospective insurance claims study.

Methods: Adult patients with DED and $\geq 1$ prescription claim for CYC or LIF (first claim = index date) in the IBM $\left.^{(}\right)$MarketScan ${ }^{\circledR}$ databases from July 2016 to February 2018 were identified. Eligible patients had continuous medical and pharmacy benefits in the 12 months pre- and post-index periods, and no prior use of the index medication. The proportion of days covered (PDC), adherence, non-persistence, discontinuation, and switching were examined over the 12-month post-index period.

Results: This study included $6537 \mathrm{CYC}$ and 3235 LIF patients. The adherence rate was 5.9\% for CYC and 9.7\% for LIF; the median PDC was 0.3 for both cohorts. Overall, 70.8\% of CYC and $64.4 \%$ of LIF patients discontinued treatment with median days to discontinuation of 89 and 29, respectively. Non-persistence was $7.1 \%$ for CYC and $6.8 \%$ for LIF (median days to discontinuation: 89 and 105). In addition, 5.0\% switched from $\mathrm{CYC}$ to LIF, and 9.6\% switched from LIF to CYC over the post-index period.

Conclusion: Over $60 \%$ of DED patients discontinued treatment within 12 months of initiation; the median time to discontinuation was 3 months for CYC and 1 month for LIF. Although this analysis did not capture the reasons why patients discontinued treatment, the results demonstrate there likely exists a significant unmet need amongst DED patients.

Keywords: dry eye disease, adherence, persistence, cyclosporine ophthalmic emulsion, lifitegrast ophthalmic solution

\section{Introduction}

Dry eye disease (DED) is a common chronic condition that affects $4 \%$ to $14.6 \%$ of the United States (US) adult population. ${ }^{1-3}$ Triggered or sustained by inflammation, DED is characterized by symptoms of visual disturbances, eye discomforts, and dryness due to tear film instability that requires long-term treatment. ${ }^{2,4}$ In 2017 the Tear Film \& Ocular Surface Society Dry Eye Workshop II (TFOS DEWS II) defined DED as

a multifactorial disease of the ocular surface characterized by a loss of homeostasis of the tear film, and accompanied by ocular symptoms, in which tear film instability and hyperosmolarity, ocular surface inflammation and damage, and neurosensory abnormalities play etiological roles. ${ }^{4}$ 
Ocular surface health is maintained by a functional lacrimal unit consisting of tear-secreting glands and ocular surface. When either tear-secreting glands or ocular surface does not function properly, the tear film would become unstable and inflammation of the ocular surface would occur, leading to DED. ${ }^{5,6}$

DED may result from or be exacerbated by hormonal changes, age, systemic autoimmune diseases, environmental conditions (such as pollution, low humidity, and sick building syndrome), surgical interventions, certain preservatives in topical medications (e.g. benzalkonium chloride) and systemic medications (e.g., antihistamines, antidepressants, anxiolytics, and isotretinoin). ${ }^{4}$ It is more prevalent among women than men and the prevalence increases with age. ${ }^{1}$ DED has been shown to contribute to difficulties with everyday activities, including driving, using a computer, reading, and completing professional work. ${ }^{7}$ Treatment options include artificial tears, anti-inflammatory treatments, immunosuppressants, and antibiotics., ${ }^{8,9}$ Currently, the Food and Drug Administration has approved two antiinflammatory treatments for DED that are commercially available for chronic use: cyclosporine ophthalmic emulsion $0.05 \%$ (CYC), approved in 2003 to increase tear production in patients with reduced tear production presumed due to ocular inflammation, and lifitegrast 5\% ophthalmic solution (LIF), approved in July 2016 for the treatment of signs and symptoms of dry eye disease. Side effects, as well as delayed onset of effect, have been reported with these two anti-inflammatory treatments. Burning and stinging upon instillation are the most common treatment-related side effects reported with CYC use ${ }^{10}$ while dysgeusia is a unique side effect reported by patients using LIF. ${ }^{11}$ To date, there is no published evidence examining adherence patterns among patients using CYC or LIF. The primary objective of this study was to assess real-world patterns of CYC and LIF use among patients with DED using a large US insurance claims database.

\section{Methods}

\section{Data Sources}

This retrospective cohort analysis was conducted with the IBM $^{\circledR} \quad$ MarketScan ${ }^{\circledR} \quad$ Commercial and Medicare Supplemental Databases from July 1, 2015 to February 28, 2018. These databases contain inpatient and outpatient medical claims and outpatient pharmacy claims, along with enrollment information, for individuals with insurance through self-insured employers or health plans and those with supplemental Medicare insurance paid for by their current or former employer. The data were previously collected, statistically de-identified, and were compliant with the Health Insurance Portability and Accountability Act; therefore, approval from an Institutional Review Board was not required.

\section{Patient Selection Criteria}

Patients were selected if they had at least one prescription filled for CYC or LIF at any time from July 1, 2016 through February 28, 2018 (study period). The first CYC or LIF pharmacy claim within the study period was defined as the index date, and each patient was categorized into either the CYC or LIF cohort based on the drug initiated on the index claim (index drug). Additional criteria required patients to be 18 years of age or older on the index date, have at least one non-rule-out medical claim with an International Classification of Diseases, Ninth Revision (ICD-9) or Tenth Revision (ICD-10) code for DED in the 12 months prior to the index date (ICD-9: 375.15; ICD-10: H04129, H04123, H04122, and H04121), and have at least 12 months of continuous enrollment with medical and pharmacy benefits prior to (pre-index period) and following (post-index period) the index date. Patients were excluded if they had a claim for the index medication during the pre-index period or any adjudication issues on the index drug claim.

\section{Outcomes}

The primary outcomes of this analysis were treatment patterns, including adherence, persistence, discontinuation, re-initiation, and switching of treatments, measured during the 12-month post-index period. Proportion of days covered (PDC) was calculated as the total days' supply divided by the number of days (365 days) in the followup period, with adherent defined as $\mathrm{PDC} \geq 80 \%{ }^{12}$ Nonpersistence was defined as no refill within 120 days for CYC and 90 days for LIF after the previous days' supply was exhausted. Among patients who were non-persistent, time to non-persistence was calculated as the number of days from treatment initiation to the last day of supply prior to the 120-day gap for CYC and 90-day gap for LIF. A patient was considered to have discontinued the index drug if he/she had no refill within 150 days for CYC and 120 days for LIF after the previous days' supply was exhausted. Time to discontinuation was measured as the number of days from treatment initiation to the last day of supply prior to the discontinuation gap specified for each 
drug. If a patient had at least one index drug claim after the discontinuation date, he/she was classified as reinitiating the index therapy. Switching from CYC to LIF or from LIF to CYC was identified if there was a claim for the non-index drug before the discontinuation gap. Switching and discontinuation were mutually exclusive.

\section{Patient Characteristics}

Demographic characteristics were measured on the index date based on enrollment information. Clinical characteristics were measured during the 12-month pre-index period and included eye related comorbid conditions, autoimmune disorders, other comorbid conditions, surgical interventions (including lid surgery and refractive surgery), concomitant medications, and prescribing physician specialty. All baseline comorbid conditions were defined as having at least one ICD-9 or ICD-10 code during the 12-month pre-index period. Medication usage during the pre-index period was identified using the National Drug Codes.

\section{Statistical Analyses}

Descriptive analyses were conducted for the CYC and LIF cohorts separately. Continuous measures were presented as mean, standard deviation (SD), and median. Categorical measures were presented as counts and percentages. SAS version 9.4 was used for statistical analysis. Time to

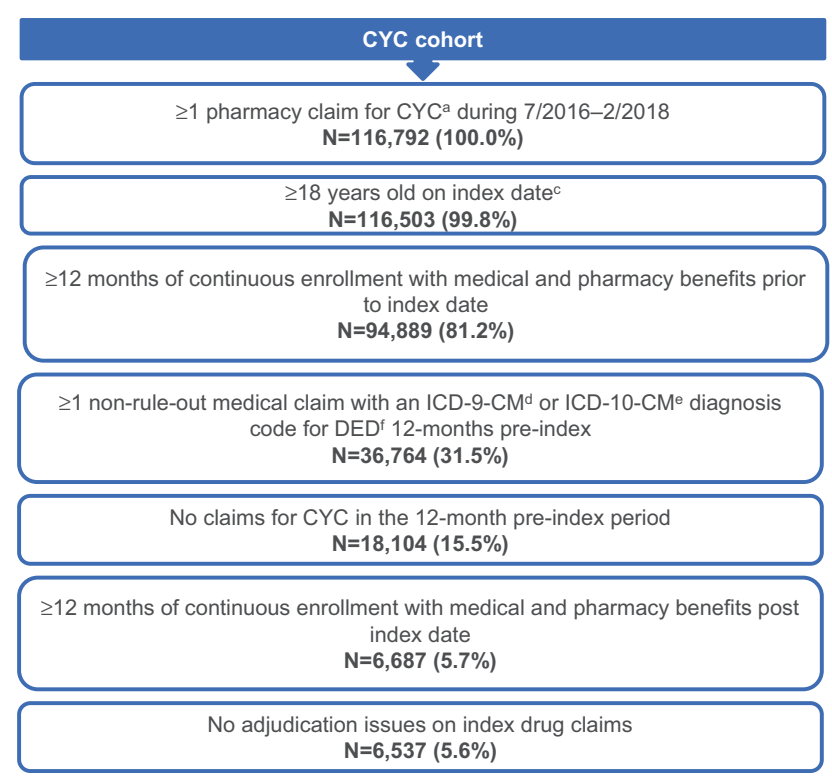

discontinuation of CYC and LIF was examined using Kaplan-Meier curves. Patients who switched treatments between CYC and LIF were censored on their switch date.

\section{Results}

\section{Study Population}

More than 154,000 patients in the MarketScan databases had $\geq 1$ claim for either CYC or LIF from July 1, 2016 through February 28, 2018. After applying the inclusion and exclusion criteria, 6537 CYC patients, and 3235 LIF patients were included in the final study population (Figure 1).

The majority of CYC and LIF patients were female, $5408(82.7 \%)$ and 2649 (81.9\%), respectively (Table 1). CYC patients were on average 60.1 (SD: 13.7) years old, and $2353(36.0 \%)$ patients were between 55 to 64 years of age. LIF patients were younger (mean age: 56.8 years; SD: 12.6), and 1289 (39.8\%) were also between ages 55 to 64 . Patients resided primarily in the Northeast (CYC: 1833 [28.0\%]; LIF: 886 [26.8\%]) and the South (CYC: 2818 [43.1\%]; LIF: 1491 [46.1\%]) and lived in urban areas (CYC: 5811 [88.9\%]; LIF: 2921 [90.3\%]). Over one-third of patients had commercial insurance, and more than half had a preferred provider organization health plan type.

A total of 1207 (18.5\%) CYC patients and 752 (23.2\%) LIF patients visited an ophthalmologist or optometrist within 14 days prior to or on the index date (Table 2).

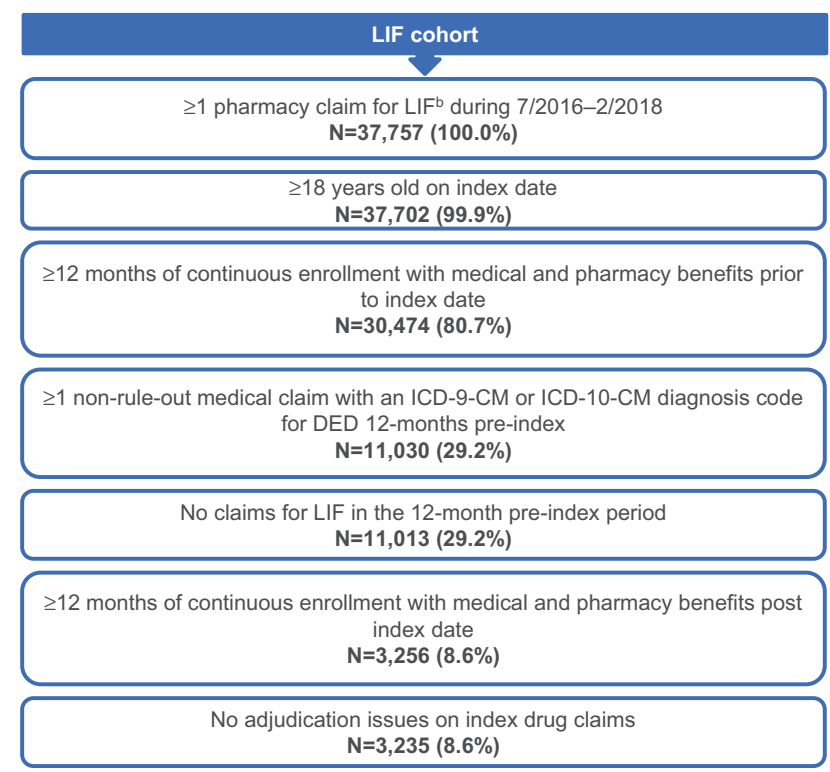

Figure I Patient attrition for the CYC and LIF cohorts.

Notes: ${ }^{\text {a } C Y C: ~ C y c l o s p o r i n e ~ o p h t h a l m i c ~ e m u l s i o n ~} 0.05 \%$. ${ }^{b}$ LIF: Lifitegrast $5 \%$ ophthalmic solution. ${ }^{\mathrm{c}}$ The date of the first CYC or LIF pharmacy claim within the study period was defined as the index date. ${ }^{\mathrm{d}} \mathrm{CCD}-9-\mathrm{CM}$ : International Classification of Diseases, Ninth Revision, Clinical Modification. ${ }^{\mathrm{e}} \mathrm{ICD}-\mathrm{I0-CM}$ : International Classification of Diseases, Tenth Revision, Clinical Modification.'DED: Dry eye disease. 
Table I Demographic Characteristics

\begin{tabular}{|c|c|c|c|c|}
\hline \multirow[b]{2}{*}{ Age (Mean, SD ${ }^{c}$ ) } & \multicolumn{2}{|c|}{$\begin{array}{l}C Y C^{a} \\
(N=6537)\end{array}$} & \multicolumn{2}{|c|}{$\begin{array}{l}\text { LIF }^{b} \\
(N=3235)\end{array}$} \\
\hline & 60.1 & 13.7 & 56.8 & 12.6 \\
\hline \multicolumn{5}{|l|}{ Age Categories (N, \%) } \\
\hline $18-24$ & 84 & $1.3 \%$ & 42 & $1.3 \%$ \\
\hline $25-34$ & 179 & $2.7 \%$ & 125 & $3.9 \%$ \\
\hline $35-44$ & 493 & $7.5 \%$ & 296 & $9.1 \%$ \\
\hline $45-54$ & 1310 & $20.0 \%$ & 802 & $24.8 \%$ \\
\hline $55-64$ & 2353 & $36.0 \%$ & 1289 & $39.8 \%$ \\
\hline $65-74$ & 1107 & $16.9 \%$ & 410 & $12.7 \%$ \\
\hline $75+$ & 1011 & $15.5 \%$ & 271 & $8.4 \%$ \\
\hline Female (N, \%) & 5408 & $82.7 \%$ & 2649 & $81.9 \%$ \\
\hline \multicolumn{5}{|l|}{ Geographic Region (N, \%) } \\
\hline Northeast & 1833 & $28.0 \%$ & 866 & $26.8 \%$ \\
\hline North Central & 1200 & $18.4 \%$ & 492 & $15.2 \%$ \\
\hline South & 2818 & $43.1 \%$ & $149 \mid$ & $46.1 \%$ \\
\hline West & 662 & $10.1 \%$ & 372 & $11.5 \%$ \\
\hline Unknown & 24 & $0.4 \%$ & 14 & $0.4 \%$ \\
\hline \multicolumn{5}{|l|}{ Insurance Plan Type (N, \%) } \\
\hline Comprehensive & 1023 & $15.6 \%$ & 246 & $7.6 \%$ \\
\hline Exclusive Provider Organization & 47 & $0.7 \%$ & 32 & $1.0 \%$ \\
\hline Health Maintenance Organization & 468 & $7.2 \%$ & 174 & $5.4 \%$ \\
\hline Point of Service & 416 & $6.4 \%$ & 223 & $6.9 \%$ \\
\hline Preferred Provider Organization & 3718 & $56.9 \%$ & 1945 & $60.1 \%$ \\
\hline Point of Service with Capitation & 96 & $1.5 \%$ & 15 & $0.5 \%$ \\
\hline Consumer Directed Health Plan & 459 & $7.0 \%$ & 377 & $11.7 \%$ \\
\hline High Deductible Health Plan & 244 & $3.7 \%$ & 201 & $6.2 \%$ \\
\hline Unknown & 66 & $1.0 \%$ & 22 & $0.7 \%$ \\
\hline \multicolumn{5}{|l|}{ Population Density (N, \%) } \\
\hline Urban & 5811 & $88.9 \%$ & 2921 & $90.3 \%$ \\
\hline Rural & 703 & $10.8 \%$ & 300 & $9.3 \%$ \\
\hline Unknown & 23 & $0.4 \%$ & 14 & $0.4 \%$ \\
\hline \multicolumn{5}{|l|}{ Primary Payer (N, \%) } \\
\hline Commercial & 4388 & $67.1 \%$ & 2545 & $78.7 \%$ \\
\hline Medicare & 2149 & $32.9 \%$ & 690 & $21.3 \%$ \\
\hline \multicolumn{5}{|l|}{ Index Year (N, \%) } \\
\hline 2016 & 5348 & $81.8 \%$ & 2351 & $72.7 \%$ \\
\hline 2017 & 1189 & $18.2 \%$ & 884 & $27.3 \%$ \\
\hline
\end{tabular}

Notes: ${ }^{a}$ CYC: Cyclosporine ophthalmic emulsion $0.05 \%$; ${ }^{b}$ LIF: Lifitegrast $5 \%$ ophthalmic solution; 'SD: Standard Deviation.

The most frequently reported eye-related comorbidities for both CYC and LIF during the pre-index period were allergic conjunctivitis, visual disturbance, and blepharitis. Other commonly diagnosed comorbidities included thyroid dysfunction, anxiety, and depression. Lid surgery occurred in $506(5.2 \%)$ patients, and refractive surgery occurred in $734(7.5 \%)$ patients.
Table 2 Baseline Clinical Characteristics

\begin{tabular}{|c|c|c|c|c|}
\hline \multirow[b]{2}{*}{$\begin{array}{l}\text { Eye related comorbid } \\
\text { conditions }(\mathbf{N}, \%)\end{array}$} & \multicolumn{2}{|c|}{$\begin{array}{l}C C^{a} \\
(N=6537)\end{array}$} & \multicolumn{2}{|c|}{$\begin{array}{l}\text { LIF }^{\mathrm{b}} \\
(\mathrm{N}=3235)\end{array}$} \\
\hline & & & & \\
\hline Allergic conjunctivitis & 599 & $9.2 \%$ & 378 & $11.7 \%$ \\
\hline Visual disturbance & 353 & $5.4 \%$ & 187 & $5.8 \%$ \\
\hline Blepharitis & 854 & $13.1 \%$ & 521 & $16.1 \%$ \\
\hline \multicolumn{5}{|l|}{$\begin{array}{l}\text { Major autoimmune disorders } \\
(\mathrm{N}, \%)\end{array}$} \\
\hline Rheumatoid arthritis & 340 & $5.2 \%$ & 168 & $5.2 \%$ \\
\hline Sjogren's syndrome & 379 & $5.8 \%$ & 224 & $6.9 \%$ \\
\hline \multicolumn{5}{|l|}{$\begin{array}{l}\text { Other Comorbid conditions } \\
(\mathrm{N}, \%)\end{array}$} \\
\hline Anxiety & 1102 & $16.9 \%$ & 549 & $17.0 \%$ \\
\hline Depression & 923 & $14.1 \%$ & 468 & $14.5 \%$ \\
\hline Diabetes & 1027 & $15.7 \%$ & 370 & $11.4 \%$ \\
\hline Fatigue & 810 & $12.4 \%$ & 407 & $12.6 \%$ \\
\hline Menopause & 1834 & $28.1 \%$ & 1002 & $31.0 \%$ \\
\hline Thyroid dysfunction & 1567 & $24.0 \%$ & 754 & $23.3 \%$ \\
\hline \multicolumn{5}{|l|}{ Surgery (N, \%) } \\
\hline Lid surgery & 318 & $4.9 \%$ & 188 & $5.8 \%$ \\
\hline $\begin{array}{l}\text { Refractive surgery (includes } \\
\text { Lasik and cataract surgery) }\end{array}$ & 495 & $7.6 \%$ & 239 & $7.4 \%$ \\
\hline \multicolumn{5}{|l|}{ Medications (N, \%) } \\
\hline Antidepressants & 2167 & $33.1 \%$ & 1094 & $33.8 \%$ \\
\hline Anxiety medication & 2388 & $36.5 \%$ & 1200 & $37.1 \%$ \\
\hline High blood pressure medication & 3300 & $50.5 \%$ & 1362 & $42.1 \%$ \\
\hline Hormone replacement therapy & 823 & $12.6 \%$ & 445 & $13.8 \%$ \\
\hline Topical allergy medication & 913 & $14.0 \%$ & 658 & $20.3 \%$ \\
\hline Topical glaucoma medication & 275 & $4.2 \%$ & 136 & $4.2 \%$ \\
\hline Topical preservatives $^{c}$ & 3096 & $47.4 \%$ & 1753 & $54.2 \%$ \\
\hline \multicolumn{5}{|l|}{$\begin{array}{l}\text { Prescribing physician specialty } \\
(\mathrm{N}, \%)^{\mathrm{d}}\end{array}$} \\
\hline Ophthalmologist & 657 & $10.1 \%$ & 318 & $9.8 \%$ \\
\hline Optometrist & 550 & $8.4 \%$ & 434 & $13.4 \%$ \\
\hline Primary care & 927 & $14.2 \%$ & 367 & $11.3 \%$ \\
\hline Rheumatologist & 89 & $1.4 \%$ & 32 & $1.0 \%$ \\
\hline Other & 1073 & $16.4 \%$ & 572 & $17.7 \%$ \\
\hline Missing & 3329 & $51.0 \%$ & 1550 & $48.0 \%$ \\
\hline
\end{tabular}

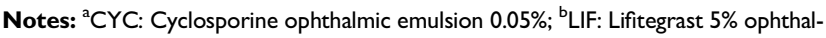
mic solution; 'Preservatives include BAK, chlorobutanol, benzododecinium bromide, purite, sofzia, methylparaben/propylparaben, thimerosal, phenylmercuric nitrate, phenylmercuric acetate, sorbic acid, sodium perborate or polyquaternium-I; ${ }^{\mathrm{d}}$ Prescribing physician specialty was measured 14 days before or on the index date.

\section{Adherence Patterns}

Adherence was low during the 12-month post-period, but it was higher for LIF (384 [9.7\%]) than for CYC (341 [5.9\%]). Both mean and median PDC were 0.3 for both cohorts (approximately 4 months) (Figure 2). Non-persistence 

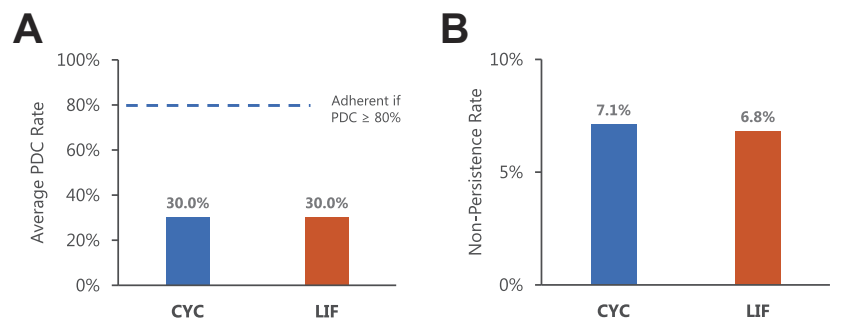

Figure 2 Mean proportion of days covered (PDC) and non-persistence ${ }^{\text {a }}$ over the 12-month post-index period. (A) Mean PDC, (B) Non-persistence.

Notes: ${ }^{a}$ Non-persistence calculation excludes patients who discontinued treatment. Abbreviations: CYC, Cyclosporine ophthalmic emulsion 0.05\%; LIF, Lifitegrast 5\% ophthalmic solution.

occurred in 461 (7.1\%) CYC patients and 220 (6.8\%) LIF patients, with a median of 89 and 105 days from initiation to non-persistence, respectively.

Overall, 4631 (70.8\%) CYC patients and 2082 (64.4\%) LIF patients discontinued their treatment within 12 months of initiation, with a median of 89 and 29 days, respectively (Figure 3). Among those who discontinued treatment, a higher proportion of CYC patients reinitiated treatment (1029 [15.7\%]) than LIF patients (292 [9.0\%]), with the median time to re-initiation of 206 days and 174 days, respectively. Overall, more patients switched from LIF to CYC (312 [9.6\%]) than patients who switched from CYC to $\operatorname{LIF}(325[5.0 \%])$. The median time to switching occurred approximately four months (124 days) after initiation for CYC patients and approximately two and a half months (76 days) after initiation for LIF patients.

According to the Kaplan-Meier analysis, the largest decrease in treatment continuation occurred around 30 days for LIF and 90 days for CYC (Figure 4). At 12 months post-index, 1026 (31.7\%) LIF patients and 2073 (27.5\%) CYC patients remained on treatment.

\section{Discussion}

This retrospective study utilized a large, real-world US claims database to evaluate adherence patterns among 9772 DED patients initiating therapy on either CYC or LIF from July 2016 to February 2018. Low adherence and high discontinuation were observed among patients initiating CYC or LIF. To our knowledge, this is the first study that examined adherence patterns of patients initiating
A

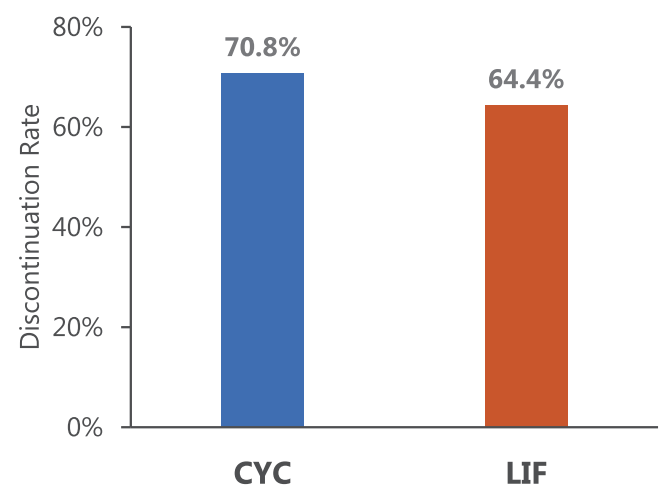

C

$5.0 \%$ of patients switched from CYC to LIF Median time to switching: 124 days

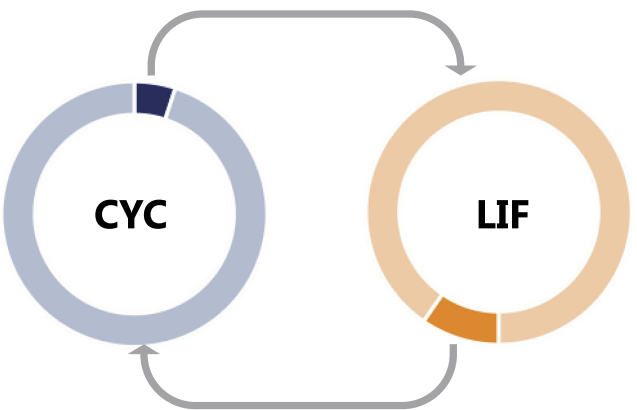

$9.6 \%$ of patients switched from LIF to CYC Median time to switching: 76 days
B

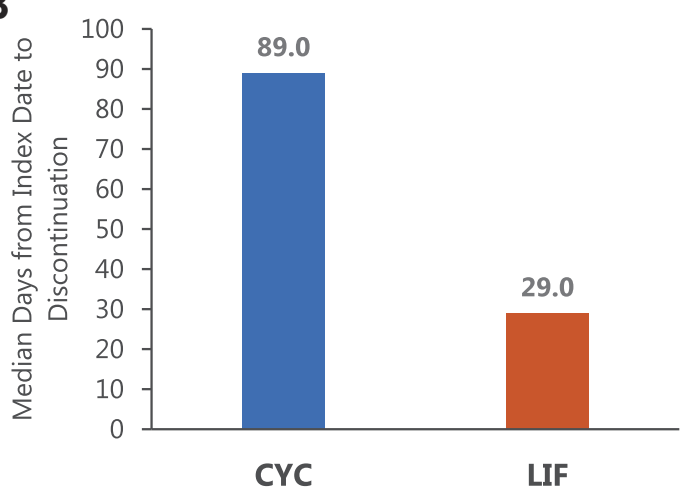

D

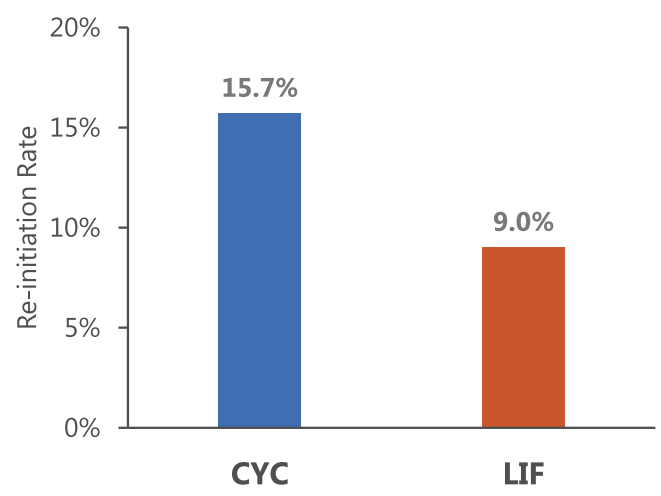

Figure 3 Discontinuation, switching, and re-initiation rates over the 12-month post-index period. (A) Discontinuation, (B) Median days to discontinuation, (C) Switching, (D) Re-initiation.

Abbreviations: CYC, Cyclosporine ophthalmic emulsion 0.05\%; LIF, Lifitegrast 5\% ophthalmic solution. 


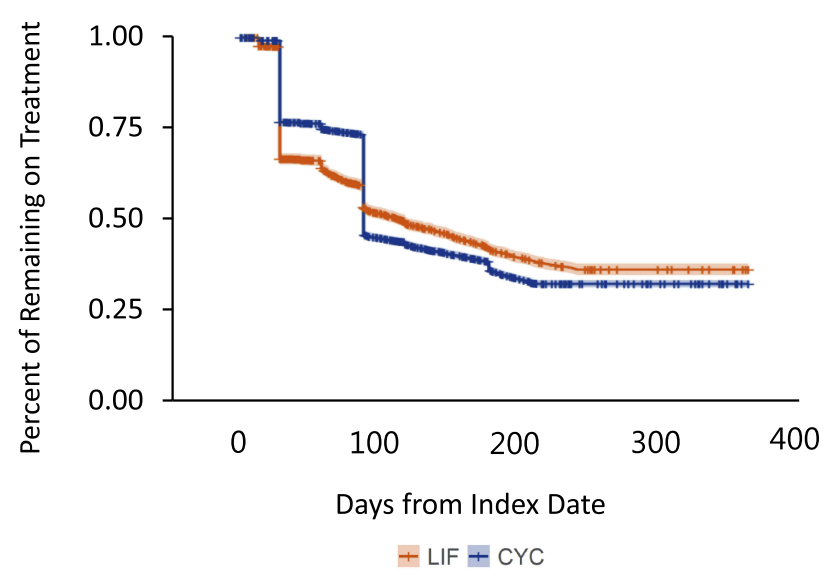

Figure 4 Kaplan-Meier curve on time to discontinuation. ${ }^{a}$ Notes: ${ }^{a}$ Patients who switched were censored at the date of switching. Abbreviations: CYC, Cyclosporine ophthalmic emulsion 0.05\%; LIF, Lifitegrast 5\% ophthalmic solution.

therapy on either CYC or LIF to capture the real-world utilization of both treatments. In the current study, adherence for both CYC and LIF was low with only 384 (5.9\%) of CYC and 314 (9.7\%) of LIF patients having a PDC $\geq$ $80 \%$ over a 12 -month follow-up period. Furthermore, both the mean and median PDC for both cohorts was roughly 4 months. This finding is consistent with a retrospective analysis by Stonecipher et al, ${ }^{13}$ who reported that patients with DED filled an average of 4.4 months' supply of CYC over a 12-month period.

Dry eye disease is a chronic, progressive disease that requires long-term treatment, particularly when there is an underlying inflammatory cause. However, findings from this study suggest that the majority of patients discontinued treatment within one year. Clinical studies have demonstrated that continued use of CYC can reduce the signs and symptoms (such as Schirmer test) of DED over 24 months. ${ }^{14,15}$ Discontinuation of CYC may lead to disease progression, thus indicating the necessity for maintenance therapy. ${ }^{15}$

Low adherence and high rates of discontinuation suggest that there may be significant unmet needs among patients with DED that is not being addressed by the currently available immunomodulatory agents. The current claims database analysis did not capture information as to why patients could not stay on treatment. Possible explanations for low adherence could be due to financial considerations, human behavior regarding chronic medication use, the efficacy of treatment, or adverse side effects. For example, in a chart review study published by Mah et al, ${ }^{16}$ burning and stinging associated with initial use of topical cyclosporine were reported as the common reasons for early discontinuation. Long term use of preservatives such as benzalkonium chloride in topical medications may cause adverse events, ${ }^{17}$ which could also lead to discontinuation of therapy in DED patients. Low adherence could also be attributed to the high cost of medication. A retrospective study using the Medical Expenditure Panel Survey found that the mean medication expenditure per patient for DED increased from \$55 in 2001-2002 to $\$ 299$ in 2005-2006, and was predominantly due to the introduction of CYC. ${ }^{18}$ Cost saving medication non-adherence, in which patients report taking smaller doses or skipping doses, due to the cost of medicine, has been reported among glaucoma patients. ${ }^{19,20}$ Another reason for the high discontinuation could be the lag time among patients between treatment initiation and experiencing symptomatic relief, particularly with CYC. Patients typically must be on consistent treatment for between 3 to 6 months before experiencing clinical benefits; this can discourage patients from continuing treatment, particularly when they require quicker resolution of their dry eye symptoms. Finally, low adherence could also be driven by other factors such as stretching the prescription usage lasting longer than its approved use. Based on these findings, it is evident that there is room for other treatment options that may be able to address some of these potential reasons for low adherence associated with the current treatments. Further research is needed to understand the drivers of low adherence and high discontinuation rates among patients initiating CYC or LIF.

This study was limited to individuals with commercial health coverage or private Medicare supplemental coverage. Consequently, the results of this analysis may not be generalizable to DED patients with other insurance or without health insurance coverage. Furthermore, the results of this study should be interpreted within the limitations of those inherent in any retrospective claims database analysis. First, patients were identified through administrative claims data as opposed to medical records. Therefore, the presence of a diagnostic code does not guarantee the presence of disease and misclassification of DED may have occurred due to data coding limitations and data entry error. Additionally, medication adherence was based on filled prescription claims. While prescription claims indicate that a prescription for DED was filled, they do not provide information on whether and how the patients used the medication. Therefore, we cannot know 
for certain if patients actually take their prescribed dry eye medications.

\section{Conclusions}

Low adherence and high discontinuation rates were observed among patients with DED initiating on currently available immunomodulatory agents, CYC or LIF. During the first 12 months following CYC or LIF initiation among patients with DED, the overall adherence was low at $30 \%$. Approximately two-thirds of patients discontinued treatment, and the median time to discontinuation was three months for CYC and one month for LIF. Although this analysis did not capture the reasons why patients discontinued treatment, the results demonstrate there may be significant unmet needs among patients with DED that is not being addressed by the currently available immunomodulatory agents.

\section{Acknowledgments}

The abstract of this paper was presented as a poster with interim findings at American Society of Cataract and Refractive Surgery (ASCR) annual meeting 2019 and the Academy of Managed Care Pharmacy (AMCP) annual meeting 2019. The ASCR poster's abstract can be accessed via https://ascrs.confex.com/ascrs/19am/meetingapp.cgi/ Paper/53018 (accessed on August 22, 2019). The AMCP poster is an encore presentation. This study was sponsored by Sun Pharmaceutical Industries Ltd, Princeton, NJ.

\section{Disclosure}

A. Ogundele and Y. Zhao are employed by Sun Pharmaceutical Industries. DE. White is affiliated with SkyVision Centers, and is a consultant for Sun Pharmaceutical Industries, Shire/Takeda Pharmaceuticals, Allergan, TearLab, Kala, and Eyevance. PM. Karpecki is a consultant for Aerie Pharmaceuticals, Akorn, Alcon, Allergan, Anthem, Avellino Labs, Bausch + Lomb, Beaver Visitech, BioTissue, Blephex, Bruder Healthcare, Cambium, DGH Technology, Essilor, EyeBrain/Neurolens, EyeGate, Eyemaginations/Rendia, Eyevance, Focus Labs, iCare USA, Imprimis, Ivantis, Jobson Medical Information/Web MD, Johnson \& Johnson Vision, Konan Medical, MacuHealth, Maculogix, Notal Vision, Novartis, Oasis Medical, Ocular Sciences, Oculus, OcuMedic, OcuSoft, Oyster Point Medical, PECAA, Quark Pharmaceuticals, Refocus, Reichert/Ametek, Retina Sciences/EyeCheck, RxSight, Science Based Health, Sentiss Pharmaceuticals, SensiMed, Shire Pharmaceuticals, Sight Sciences,
TelScreen, Total Eyecare Partners, Topcon, Visant Medical, Visionix, Vital Tears, Vmax, and Zeiss. PM. Karpecki is on the Board of Directors for Bruder Healthcare, LensTechs, Optometric Medical Solutions, Silk Technologies, and TearLab. PM. Karpecki also reports personal fees from Sun Pharmaceuticals, outside the submitted work. N, Fulcher, A. Acs and L. Moore-Schiltz are employees of IBM Watson Health, which received funding from Sun Pharmaceuticals Industries to conduct this study. The authors report no other conflicts of interest in this work.

\section{References}

1. Farrand KF, Fridman M, Stillman IO, Schaumberg DA. Prevalence of diagnosed dry eye disease in the united states among adults aged 18 years and older. Am J Ophthalmol. 2017;182:90-98. doi:10.1016/j. ajo.2017.06.033

2. The definition and classification of dry eye disease: report of the Definition and Classification Subcommittee of the International Dry Eye WorkShop (2007). Ocul Surf. 2007;5(2):75-92. doi:10.1016/ S1542-0124(12)70081-2

3. Dana R, Bradley JL, Guerin A, et al. Estimated prevalence and incidence of dry eye disease based on coding analysis of a large, all-age United States health care system. Am J Ophthalmol. 2019. [ePub ahead of print]. doi:10.1016/j.ajo.2019.01.026

4. Nelson JD, Craig JP, Akpek EK, et al. TFOS DEWS II Introduction. Ocul Surf. 2017;15(3):269-275. doi:10.1016/j.jtos.2017.05.005

5. Stern ME, Beuerman RW, Fox RI, Gao J, Mircheff AK, Pflugfelder SC. The pathology of dry eye: the interaction between the ocular surface and lacrimal glands. Cornea. 1998;17(6):584-589. doi:10. 1097/00003226-199811000-00002

6. Perry HD. Dry eye disease: pathophysiology, classification, and diagnosis. Am J Manag Care. 2008;14(3 Suppl):S79-S87.

7. Miljanovic B, Dana R, Sullivan DA, Schaumberg DA. Impact of dry eye syndrome on vision-related quality of life. Am J Ophthalmol. 2007;143(3):409-415. doi:10.1016/j.ajo.2006.11.060

8. Behrens A, Doyle JJ, Stern L, et al. Dysfunctional tear syndrome: a Delphi approach to treatment recommendations. Cornea. 2006;25 (8):900-907. doi:10.1097/01.ico.0000214802.40313.fa

9. Jones L, Downie LE, Korb D, et al. TFOS DEWS II management and therapy report. Ocul Surf. 2017;15(3):575-628. doi:10.1016/j.jtos.20 17.05.006

10. Sall K, Stevenson OD, Mundorf TK, Reis BL. Two multicenter, randomized studies of the efficacy and safety of cyclosporine ophthalmic emulsion in moderate to severe dry eye disease. CsA Phase 3 study group. Ophthalmology. 2000;107(4):631-639. doi:10.1016/S0161-6420(99)00176-1

11. Xildra Package insert. Available from: https://www.accessdata.fda.gov/ drugsatfda_docs/label/2016/208073s0001bl.pdf. Accessed August 27, 2018.

12. Hugtenburg JG, Timmbers L, Elders PJ, Vervloet M, van Dijk L. Definitions, variants and causes of nonadherences with medication: a challenge to tailored interventions. Patient Prefer Adherence. 2013;7:8

13. Stonecipher KG, Chia J, Onyenwenyi A, Villanueva L, Hollander DA. Health claims database study of cyclosporine ophthalmic emulsion treatment patterns in dry eye patients. Ther Clin Risk Manag. 2013;9:409-415. doi:10.2147/TCRM.S49754

14. Rao SN. Topical cyclosporine $0.05 \%$ for the prevention of dry eye disease progression. J Ocul Pharmacol Ther. 2010;26(2):157-164. doi:10.1089/jop.2009.0091 
15. Rao SN. Reversibility of dry eye deceleration after topical cyclosporine 0.05\% withdrawal. J Ocul Pharmacol Ther. 2011;27(6):603609. doi:10.1089/jop.2011.0073

16. Mah F, Milner M, Yiu S, Donnenfeld E, Conway TM, Hollander DA. PERSIST: physician's evaluation of restasis ${ }^{\circledR}$ satisfaction in second trial of topical cyclosporine ophthalmic emulsion $0.05 \%$ for dry eye: a retrospective review. Clin Ophthalmol. 2012;6:1971. doi:10.2147/ OPTH.S30261

17. Baudouin C. Detrimental effects of preservatives in eye drops: implications for the treatment of glucoma. Acta Ophthamologica. 2008;86 (7):716-726. doi:10.1111/j.1755-3768.2008.01250.x

18. Galor A, Zheng DD, Arheart KL. Dry eye medication use and expendtures: data from the medical expenditure panel survey 2001-2005. Cornea. 2012;31:1403-1407. doi:10.1097/ICO.0b013e $31823 \mathrm{cc} 0 \mathrm{~b} 7$
19. Blumberg DM, Prager AJ, Liebmann JM, Cioffi GA, De Moraes CG. Cost-related medication nonadherence and cost-saving behaviors among patients with glaucoma before and after the implementation of medicare part D. JAMA Ophthalmol. 2015;133(9):985-996. doi:10.1001/jamaophthalmol.2015.1671

20. Friedman DS, Hahn SR, Gelb L, et al. Doctor-patient communication, health-related beliefs, and adherence in glaucoma results from the glaucoma adherence and persistency study. Ophthalmology. 2008;115(8):1320-1327, 1327.e1321-1323. doi:10.1016/j.ophtha.20 07.11 .023

\section{Publish your work in this journal}

Clinical Ophthalmology is an international, peer-reviewed journal covering all subspecialties within ophthalmology. Key topics include: Optometry; Visual science; Pharmacology and drug therapy in eye diseases; Basic Sciences; Primary and Secondary eye care; Patient Safety and Quality of Care Improvements. This journal is indexed on PubMed

Submit your manuscript here: https://www.dovepress.com/clinical-ophthalmology-journal
Central and CAS, and is the official journal of The Society of Clinical Ophthalmology (SCO). The manuscript management system is completely online and includes a very quick and fair peer-review system, which is all easy to use. Visit http://www.dovepress.com/ testimonials.php to read real quotes from published authors. 